Ann. Biol. anim. Bioch. Biophys., 1964, 4 (2), 163-187

\title{
MISE AU POINT SUR LA SÉPARATION, L'IDENTIFICATION ET LE DOSAGE DES PROTEINES DU LAIT DE VAGHE A L'EXCLUSION DES CASÉINES
}

\author{
J. GARNIER \\ Station centrale de Recherches laitières et de Technologie des Produits animaux, \\ Centre national de Recherches zootechniques, Jouy-en-Josas (Seine-et-Oise)
}

\section{PLAN}

Introduction $\ldots \ldots \ldots \ldots \ldots \ldots \ldots \ldots \ldots \ldots \ldots \ldots \ldots \ldots \ldots \ldots \ldots \ldots \ldots \ldots \ldots \ldots$

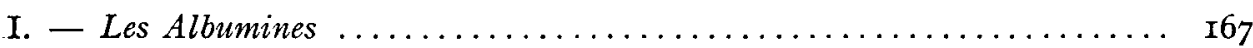

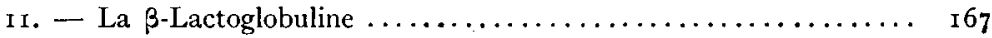

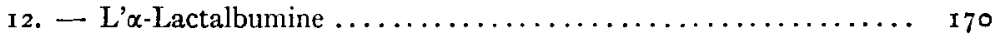

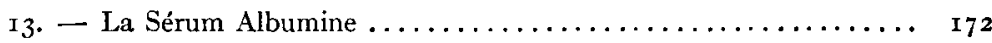

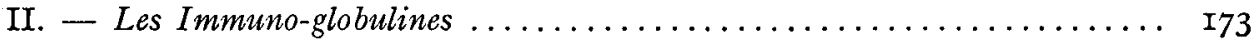

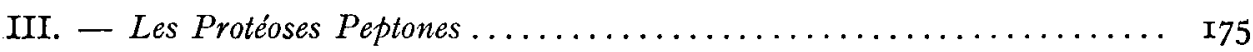

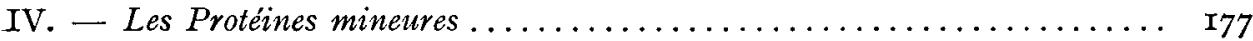

4. - La protéine rouge ou Lactotransferrine............. I 77

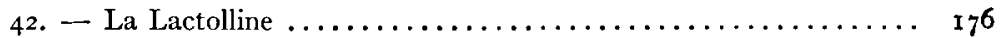

43. - Les Protéines de la membrane des globules gras ........ 179

44. - Les enzymes du lait ...................... 181

441. - Xanthine oxydase.

442. - Lactoperoxydase.

443. - Phosphatase alcaline.

444. - Lipases du lait.

445. - Amylase.

446. - Protéase.

447. - Catalase.

Références

\section{INTRODUCTION}

Parmi les produits d'origine biologique, le lait représente une source abondante de protéines, facile à recueillir et très largement utilisée par l'homme pour son alimentation. Pour le nouveau-né, il joue un rôle primordial et représente le dernier contact de ce nouveau-né avec sa mère. 
C'est certainement le lait de vache qui a été le plus étudié du fait de la facilité avec laquelle il peut être récolté en quantité importante.

On attribue généralement aux protéines du lait deux origines différentes, d'après leur lieu de synthèse : ou bien elles sont synthétisées par le tissu de la glande mammaire elle-même, ou bien elles proviennent du sang par simple filtration à partir du courant sanguin irriguant la mamelle. Ces deux origines possibles des protéines du lait ont été étudiées par analyse immunologique (d'après le procédé employé notamment par Von Gugler, Beis et Von Muralit (I959) ou en déterminant la. vitesse d'incorporation $\mathrm{du}{ }^{14} \mathrm{C}$ dans les différentes protéines (c'est la méthode adoptée par LARSON et GILLESPIE (I957). Les analyses immuno- électrophorétiques de Von Gugrear, Bein et Von Murait (I959) et de Hanson (I959) ont permis. de dénombrer dans le lait de vache $I_{5}$ à 2 I protéines antigéniques. Parmi celles-ci 7 à 8 protéines sont rencontrées exclusivement dans le lait et sont par conséquent synthétisées dans la glande mammaire. En accord avec les travaux de LARson et. GillESPIE (I957), ce groupe comprend la $\beta$-lactoglobuline, l' $\alpha$-lactalbumine, la protéine rouge et la majeure partie des caséines en particulier la caséine $\alpha$ et la caséine $\beta$. Les autres protéines du lait (7 d'après Von GugLER, Bern et Von Murait (I959) à I4 d'après HANSON (I959)) sont, au point de vue immunologique, identiques à celles du sang et passent dans le lait par simple filtration. Tel est le cas en particulier de la sérum albumine et des immuno-globulines.

La séparation et l'identification des différents constituants protéiques du lait ont donné lieu à un nombre considérable de travaux dont nous ne ferons pas l'historique, nous contentant simplement de rapporter les procédés de séparation utilisés actuellement. Certains de ces constituants peuvent faire l'objet d'un dosage spécifique mais ils ne représentent qu'une minorité. Le plus souvent, le dosage d'un groupe de constituants est seul possible (par exemple dosages des caséines, des globulines, des protéoses peptones).

Bien que la caséine figure parmi les préparations protéiques les plus anciennement mises au point (MÜLDER (I838) l'obtenait par addition de vinaigre à du lait puis redissolution à l'aide de salpêtre) son étude ultérieure a révélé une grande complexité en raison d'interactions très fortes entre ses divers constituants dont le nombre a été évalué à $2 \mathrm{I}$ par WAKe et BALDWIN (I96I).

Comme la séparation et l'identification des caséines est encore à l'heure actuelle une question complexe, controversée et en pleine évolution, nous avons limité notre étude aux autres protéines du lait, appelées protéines du lactosérum ou encore protéines solubles. Nous pouvons les définir comme les protéines restant en solution après acidification du lait à $\mathrm{pH} 4,6$. C'est une définition plus pratique que rigoureusecar les caséines précipitées peuvent entraîner par adsorption une partie des protéines. du lactosérum, comme c'est le cas de la protéine rouge et de la lactolline (Groves, I960 et Groves et al., I963). De plus, il existe d'autres procédés pour éliminer les caséines : précipitation par les sels neutres, précipitation du paracaséinate de calcium après action de la présure ou simplement centrifugation à $45000 \mathrm{~g}$ des micelles de caséines selon Mocouot, Alais et Chevalier (I954) ou Von Hippel et Waugh (I955). Ces procédés ne conduisent pas tous au même résultat. Én effet BrunNER et THompson (I96I) ont montré que la fraction de WEINSTEIN, obtenue après élimination des caséines par emprésurage, contenait une part importante des produits de scission résultant de l'attaque des caséines par la présure. 
Les protéines du lactosérum représentent I8 à 2I p. Ioo des protéines totales du lait de vache, soit environ $5,5 \mathrm{~g}$ à $6,5 \mathrm{~g} /$ litre d'après les déterminations faites par ROLLERI, LARSON et TOUCHBERRY (I956) en comparant plusieurs races laitières. D'après les analyses électrophorétiques de MCMEEKIN (I954) et, fig I, de LAARSON et RoLLERI (I955), $80 \mathrm{p}$. roo de ces protéines sont constituées par la $\beta$-lactoglobuline, 1' $\alpha$-lactalbumine, la sérum albumine et les immuno-globulines. Les trois premières de ces protéines ont été préparées à l'état cristallisé. Nous avons porté dans le tableau I l'importance relative de chacun des constituants d'après LARSON et ROLLERI (I955) et d'après les dosages par voie chimique d'Aschaffénburg et Drewry (I959). L'écart observé entre ces deux séries de résultats peut provenir : d'une association entre deux constituants ou d'une migration identique de deux constituants par électrophorèse ou encore dans la méthode chimique employée par AschafFENBURG

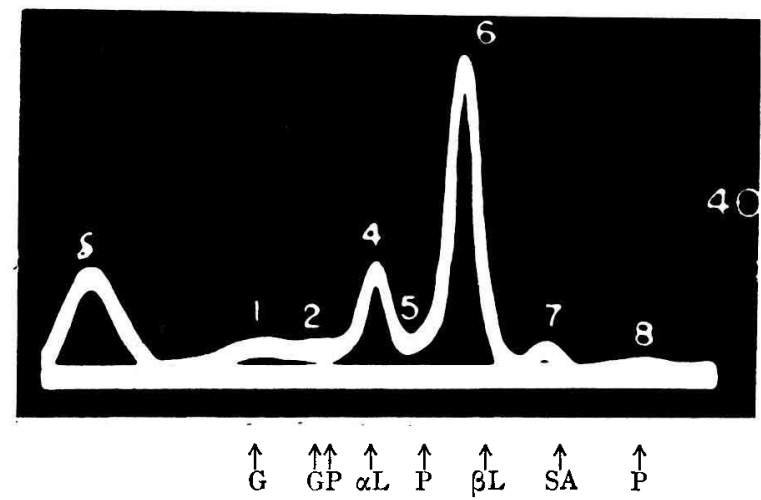

Fig. I. - Electrophorèse selon Tiseluus du laclosérum du lait de vache (LARson et Rolderi (I 955)) en tampon_véronal pH 8,6, $\Gamma / 2=0,1$. Branche ascendante. Concentration en protéines $\mathrm{r}, 9 \%$

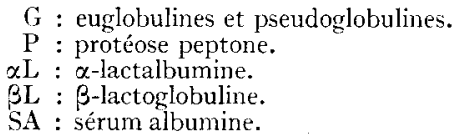

et DREWRY (I959) d'une séparation incomplète et du caractère arbitraire du coefficient servant à multiplier la teneur en azote pour obtenir la teneur en protéines. Dans l'établissement de ces pourcentages il n'est pas tenu compte des protéines mineures du lactosérum comme la protéine rouge, les protéines de la membrane des globules gras et divers enzymes qui constituent au total environ I à 2 p. Ioo. Parmi ces protéines en faible proportion, certaines peuvent jouer un rôle important, par exemple en inhibant la croissance de certains microorganismes dans le lait (lactoperoxydase d'après WRIGHT et TRAMER, I958) ou en permettant une vérification du traitement du lait par la chaleur (phosphatase alcaline.)

Nous avons classé les protéines du lactosérum en quatre groupes, la division entre les deux premiers est fondée sur le fractionnement des protéines du lait par les sels neutres, fractionnement le plus anciennement utilisé. Nous avons ensuite réuni dans un troisième groupe les protéoses peptones et dans un quatrième les constituants protéiques mineurs du lait. 
Les albumines correspondent aux protéines solubles à $\mathrm{pH}$ neutre en solution demi saturée en sulfate d'ammonium ou en solution saturée de sulfate de magnésium. On les distinguait autrefois sous le nom de lactalbumine et PEDERSEN (I936) avait décelé par ultracentrifugation les constituants $\alpha, \beta$ et $\gamma$. Le constituant $\alpha$ a été appelé $\alpha$-lactalbumine, le constituant $\beta$ a été appelé par PEDERSEN lactoglobuline en raison de sa faible solubilité en solution saline diluée au point isoélectrique et c'est CANNAN, PALMER et KIBRICK (I942) qui proposèrent de l'appeler $\beta$-lactoglobuline. Le troisième constituant est la sérum albumine identique à celle du sang. AschafFENBURG et DREWRY (1957), distinguent, en plus, deux autres constituants mineurs qui en électrophorèse, ne migrent ni avec 1' $\alpha$-lactalbumine, ni avec la sérum albumine. Ceci explique les teneurs plus faibles en albumines autres que la $\beta$-lactoglobuline obtenues par IARSON et ROLLERI (I955) comparées à celles d'ASCHAFFENBURG et DREWRy (I959) (tabl. I).

TABLEAU I

Principaux constituants protéiques du lactosérum du lait de vache normal

\begin{tabular}{|c|c|c|c|c|}
\hline & \multicolumn{2}{|c|}{$\begin{array}{l}\text { D'après LARSON } \\
\text { et RoLLERI (1955) }\end{array}$} & \multicolumn{2}{|c|}{$\begin{array}{c}\text { D'après AschaFFENBURG } \\
\text { et DREWRY (1959) }\end{array}$} \\
\hline & $\%(1)$ & $\mathrm{g} /$ litre de lait $\left({ }^{2}\right)$ & $\%(\mathbf{1})$ & g/litre de lait $\left({ }^{2}\right)$ \\
\hline Immuno-globulines & 13 & $0,7-0,8$ & 10,7 & $0,6-0,7$ \\
\hline Albumines & 68,1 & & 79,7 & \\
\hline$\beta$-lactoglobuline ......... & 43,7 & $2,4-2,9$ & 49,6 & $2,7-3,2$ \\
\hline$\alpha$-lactalbumine $\ldots \ldots \ldots \ldots \ldots$ & 19,7 & $1,1-1,3$ & & \\
\hline Sérum albumine $\ldots \ldots \ldots \ldots \ldots$ & 4,7 & $0,25-0,3$ & 30,1 & $1,7 \cdot 2,0$ \\
\hline Autres albumines $\ldots \ldots \ldots \ldots \ldots$ & 0 & - & & onstituants) \\
\hline Protéoses peptones & 18,9 & & 9,6 & $0,5-0,6$ \\
\hline Constituant $3 \ldots \ldots \ldots \ldots \ldots$ & 4,6 & $0,25-0,3$ & & \\
\hline Constituant $5 \ldots \ldots \ldots \ldots \ldots$ & 8,6 & $0,45-0,55$ & & \\
\hline Constituant $8 \ldots \ldots \ldots \ldots \ldots$ & 5,7 & $0,3-0,4$ & & \\
\hline
\end{tabular}

(1) \% des protéines du lactosérum.

(2) g/litre de lait calculés d'après une teneur en protéines du lactosérum variant entre $5,5 \mathrm{~g}$ et $6,5 \mathrm{~g} / \mathrm{litre}$.

Les globulines, appelées aussi lactoglobulines, sont insolubles à $\mathrm{pH}$ neutre en solution de sulfate d'ammonium à demi saturation ou dans le sulfate de magnésium saturé. Ellles ont été divisées par CROwTHER et RAISTRICK (I9I6) en euglobulines (insolubles dans l'eau distillée au point isoélectrique) et pseudoglobulines (solubles dans les mêmes conditions). Cette fraction globuline est essentiellement constituée par les immuno-globulines.

Enfin les protéoses peptones sont constituées par un ensemble mal connu de glycoprotéines solubles dans l'acide trichloracétique à $4 \mathrm{p}$. IOO. 
Pour chacun des constituants nous indiquerons les méthodes de séparation et nous donnerons très rapidement quelques propriétés caractéristiques permettant l'identification. Pour certains constituants nous étudierons les méthodes de dosage proposées.

\section{I. - LES ALBUNINES}

\section{II. - LA $\beta$-LACTOGLOBULINE}

La $\beta$-lactoglobuline est un constituant protéique majeur des protéines du lactosérum (tabl. I) et elle a donné lieu à de nombreux travaux dont TILLEY (Ig60) a fait une revue extensive. C'est une des rares proteines du lait, avec $l^{\prime} \alpha$-lactalbumine, préparée à 1'état cristallisé qu'il soit possible de doser spécifiquement. Elle est synthétisée par l'organisme sous deux formes au moins A et B contrôlées par un seul gène d'après AschaFFEnBurg et DREWRy (I957) $b$. L'individu hétérozygote produit un mélange de $\beta$-lactoglobuline $A$ et $B$ (environ $60 \mathrm{p}$. Ioo de $A$ et $40 \mathrm{p}$. IOo de $B$ d'après Aschaffenburg et DrEWRy (1955). La $\beta$-lactoglobuline A diffère

TABLEAU 2

Méthodes de préparation de la $\beta$-lactoglobuline du lait vache

10) Selon Cecil et Ogston (1949).

\section{Lait écrémé}

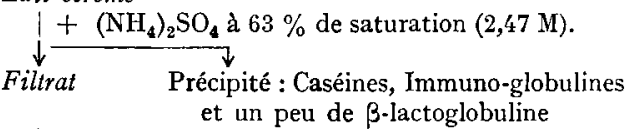

$\underset{\downarrow \text { Filtrat }}{\downarrow} \underset{\text { Précipité }}{+\left(\mathrm{NH}_{4}\right)_{2} \mathrm{SO}_{4}}$ à $82 \%$ de saturation $(3,2 \mathrm{M})$
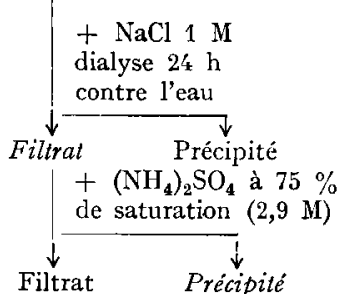

Filtrat Précipité
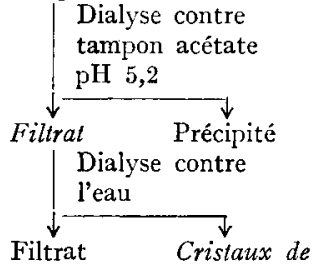

B-lactoglobuline

Recristallisation à partir du

tampon acétate pH 5,2 ou NaCl $\left.2^{\circ}\right)$ Selon Aschaffenburg et Drewry (1957)a

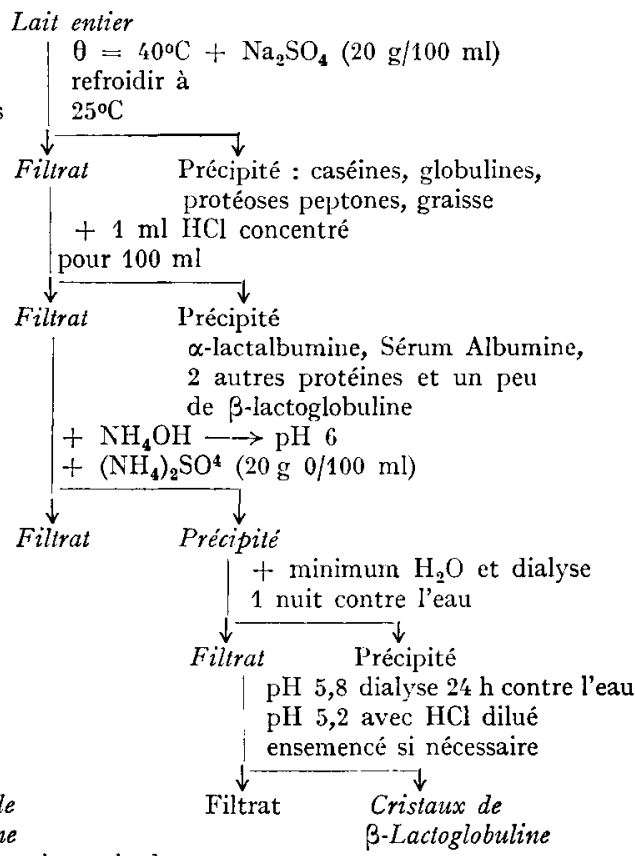


en particulier de la $\beta$-lactoglobuline $B$ par la présence d'un acide aspartique et d'une valine à la place d'un glycocolle et d'une alanine d'après PIEZ et al. (I96r) ce qui lui confère une plus grande mobilité électrophorétique et permet de les séparer l'une de l'autre (AschafFenburg et DREWRy I955, ; PIEZ et al. I96I), Une $\beta$-lactoglobuline $\mathrm{C}$ a été récemment signalée (BELL, I962).

\section{III. - Séparation}

La méthode de préparation de PALMER (I934) modifiée plus tard par CECIL et OGSTON (I949) a été souvent utilisée. Une méthode plus simple a été proposée par AschafFEnBURG et DREWRy (I957)a. Les deux techniques ont été schématisées dans le tableau 2 d'après Tilley (I960). Si la méthode de CeciL et OGston est plus longue et d'un rendement moindre, elle présente l'avantage de ne pas nécessiter l'addition d'acide ou de base qui risque d'entraîner une dénaturation partielle d'après Pedersen (I936) $b$ et Linderstrom LANG et Jacobsen (I94I). La préparation de

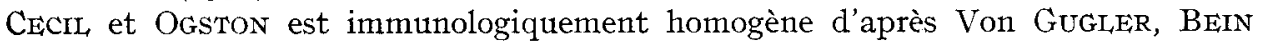
et Von Muralit (I959).

D'après AschafFEnBurg et DREWry (I957)a la quantité de $\beta$-lactoglobuline cristallisée obtenue est de I,3 à I,5 g/litre, quantité qu'il convient de comparer à la teneur totale du lait en $\beta$-lactoglobuline, soit 2,4 à $3,2 \mathrm{~g} /$ /itre (d'après JENnEss et al. (I956), Rollekr, IAARson et TOUChBERRy (I956) et AschafFEnburg et DreWRY (I959)).

Pour préparer la $\beta$-lactoglobuline A ou B il suffit d'effectuer la préparation à partir du lait provenant d'individus homozygotes A ou B. PIEz et al. (Ig6I) ont séparé les deux $\beta$-lactoglobulines à partir d'un mélange des deux, par chromatographie sur D.E.A.E.-cellulose.

\section{II2. - Identification}

La $\beta$-lactoglobuline fut la première protéine du lait à être préparée à l'état cristallisé par PALMER (I934). Le mélange de $\beta$-lactoglobuline A et B cristallise dans le système orthorhombique cependant que la $\beta$-lactoglobuline B seule, cristallise spontanément dans le système monoclinique et l'ensemencement en cristaux orthorhombiques est nécessaire pour qu'elle cristallise dans ce système. Outre la propriété de cristalliser facilement la $\beta$-lactoglobuline a été identifiée par sa mobilité électrophorétique en phase liquide ( $\mu=-5$, I en tampon véronal $\mathrm{pH} 8,4 \Gamma / 2=0, \mathrm{I}$, d'après MCMEEKIN (1954)) et elle correspond au constituant no 6 de LARSON et ROLLERI (I955). Elle correspond également au constituant $\beta$ observé par PEDERSEN (I936)a dont la constante de sédimentation $\mathrm{S}_{20}$ est égale à 2,8 à $\mathrm{pH} 5$ d'après OGSTON et Tombs (1957). Par électrophorèse sur papier à température ordinaire en tampon véronal pH 8,6 Aschaffenburg et Drewry (I955) séparent les $\beta$-lactoglobulines A et B ainsi que PIEz et al. (Ig6I) par chromatographie sur D.E.A.E.-cellulose à pH 5,8 à $5^{\circ} \mathrm{C}$. I e coefficient d'extinction de la $\beta$-lactoglobuline $\mathrm{A}$ ou $\mathrm{B}$ à $278 \mathrm{~m} \mu$ en tampon

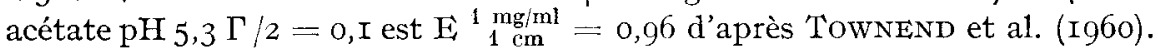

$$
\text { II3. - Dosage }
$$

Nous décrirons deux méthodes, l'une chimique l'autre immunochimique, toutes deux dosant les 2 formes $\mathrm{A}$ et $\mathrm{B}$ de $\beta$-lactoglobuline. 


\section{II3I. - Méthode de dosage chimique.}

Elle est due essentiellement à Aschaffendurg et Drewry (I959) et consiste à précipiter au cours d'une première phase toutes les protéines du lait, à l'exception des albumines, en ajoutant $20 \pm \mathrm{I} g$ de sulfate de sodium anhydre à roo $\mathrm{ml}$ de lait. Le filtrat est amené ensuite à $\mathrm{pH} 2$ par addition d'acide chlorhydrique, seules la $\beta$-lactoglobuline et les substances azotées non protéiques restent en solution (AscHAFFENBURG et Drewry (I957)a. De l'azote du filtrat (dosé par KJELDAHL), on déduit l'azote non protéique (azote soluble après précipitation des protéines du lait par 1'acide trichloracétique à I 2 p. Ioo de concentration finale). Les résultats obtenus (tabl. I) sont très semblables sinon identiques à ceux de LARSON et GIL,LESPIE (I957) obtenus en mesurant la surface du pic observé au cours de l'électrophorèse des protéines solubles selon le procédé de 'Tiseilius.

\section{Ir32. - Méthode de dosage immunochimique.}

Elle a été mise au point par LARSON et 'TWAROG (I96I) d'après la technique d'Oudin (I948). Elle consiste à superposer à une couche de gélose mélangée à un sérum anti- $\beta$-lactoglobuline, une solution contenant $\mathrm{I}_{5}$ à $70 \gamma / \mathrm{ml}$ de $\beta$-lactoglobuline dans un petit tube de $2 \mathrm{~mm}$ de diamètre intérieur et d'environ $10 \mathrm{~cm}$ de long. La solution de $\beta$-lactoglobuline diffuse dans la gélose et précipite au contact des anticorps : on mesure au pied à coulisse la distance $\mathrm{D}$ qui sépare l'interface (solution de $\beta$-lactoglobuline et gélose) du front du précipité au bout d'un temps $\mathrm{T}(24,48$ ou $72 \mathrm{~h})$. Les auteurs ont montré qu'il y avait une relation linéaire entre le rapport $D / \sqrt{T}$ et le logarithme de la concentration en $\beta$-lactoglobuline. Une courbe étalon est tracée à partir de quantités connues de $\beta$-lactoglobuline. La précision, \pm Io $p$. Ioo, est de l'ordre de celle que l'on obtient pour la mesure des concentrations par la méthode d'électrophorèse selon Tiselius. Elle est moins bonne que la méthode chimique mais cette méthode est très spécifique, très sensible et surtout elle permet de doser la $\beta$-lactoglobuline dans des milieux très complexes contenant de nombreuses autres protéines parmi lesquelles la $\beta$-lactoglobuline ne figure que dans la proportion $\mathrm{I} / \mathrm{I} O$ ooo.

Après concentration par lyophilisation il est possible de doser jusqu'à $0,5 \mathrm{\gamma} / \mathrm{ml}$ de $\beta$-lactoglobuline mais la précision est moins bonne : $\pm 20 \mathrm{p}$. Ioo.

Cette technique a l'inconvénient de dépendre de la préparation d'un anti-sérum, réactif biologique long à préparer et variable à chaque préparation : d'où la nécessité de refaire la courbe étalon pour chaque sérum et même chaque préparation de gélose. Au cours de l'immunisation il faut utiliser un antigène très purifié, LARson et TwAROG (Ig6I) ont recristallisé 8 fois la $\beta$-lactoglobuline.

\section{Ir33. - Conclusion.}

La méthode d'ASCHAFFEnBurg et DrFwry (I959) nous semble être celle qui s'applique le mieux au lait, car elle est plus précise et plus commode d'emploi. La technique de LARSON et TWAROG (I96I) se montre particulièrement utile lorsque les concentrations en $\beta$-lactoglobuline sont très faibles et que les dosages doivent se faire à partir de milieux complexes tels que par exemple les broyats de culture de tissus mammaires ou encore les fromages, les produits alimentaires à base de poudre de lait, etc. 
A divers titres, la $\beta$-lactoglobuline présente des caractéristiques intéressantes. Elle est responsable de la majorité des groupements $\mathrm{SH}$ libres qui existent dans le lait. Elle possède en commun avec la sérum albumine la propriété de former des complexes avec de nombreux métaux. La $\beta$-lactoglobuline $A$ se polymérise en dimère et tétramère dans la zone de $\mathrm{pH} 3,7$ à 5,3 alors que la $\beta$-lactoglobuline $\mathrm{B}$ reste sous forme monomère ou dimère. Les deux formes de $\beta$-lactoglobuline peuvent s'associer entre elles ('TIMASHEFF et 'TOWNEND I96 I $a$ ) et à $\mathrm{pH}<3,7$ se dissocier en deux sous-unités non interchangeables (TimashefF et Townend (I96i) $b$ et Townend, KIDDy et 'TimashefF r96I). Én raison de la grande facilité de sa préparation sous forme cristallisée, de nombreux travaux ont été effectués en ce qui concerne 1'action des enzymes protéolytiques sur la $\beta$-lactoglobuline ou sa dénaturation par chauffage ou en présence d'urée par exemple.

\section{I2. - L' $\alpha$-LACTALBUMINE}

C'est assez récemment que Gordon et Semmett' (I953), Gordon, Semmett et ZIEGLER (I954) publièrent la méthode de préparation de 1' $\alpha$-lactalbumine cristallisée, à la suite des travaux de Sørensen et Sørensen (I939). Aussi peu de travaux ont-ils été publiés concernant cette protéine qui représente environ $20 \mathrm{p}$. Ioo des protéines du lactosérum d'après LARSON et ROLLERI (I955) (tabl. I).

\section{I2I. - Séparation}

Dans le tableau 3 nous avons reporté côte à côte les deux techniques de préparation selon GoRdon et al. (I953 et I954) et d'AschaffENBURG et DREWRy (I957)a. Des deux méthodes, celle d'Aschaffenburg et DREWry semble la plus simple et présente l'avantage de conduire à la séparation de la $\beta$-lactoglobuline et de la sérum albumine dans la même suite d'opération.

Dautrevaux (I963) a présenté récemment une autre méthode de préparation permettant d'obtenir avec un bon rendement une préparation purifiée d' $\alpha$-lactalbumine. Cette préparation contient encore comme principale impureté de la $\beta$-lactoglobuline ; elle est essentiellement fondée sur un fractionnement par le sulfate d'ammonium, précipitation à $\mathrm{pH}$ acide et filtration finale sur Séphadex.

\section{2. - Identification}

L' $\alpha$-lactalbumine correspond au pic $\alpha$ d'ultracentrifugation des protéines du lactosérum d'après PEDERSEN (I936). Son coefficient de sédimentation $\mathrm{S}_{20}$ est égale à I,75 en tampon phosphate $\mathrm{pH} 7,5 \Gamma / 2=0,2$. Sa mobilité électrophorétique en tampon véronal pH 8,5 est de - 4,2 mais, d'après LARson et JENness (I955), la mobilité est portée à - 3,6 en présence des autres protéines du lactosérum, ce qui permet d'identifier le pic no 4 de l'électrophorèse selon TisELIUS (cf. fig. I) à celui de l' $\alpha$-lactalbumine contrairement aux résultats de McMEEKIN (I954). D'après Aschaffenburg et DREWRY (I957) $a$, l' $\alpha$-lactalbumine cristallise sous trois formes différentes. GORDON et ZIEGLER (I955) ont étudié sa composition en acides aminés et ont trouvé une forte teneur en tryptophane ( $7 \mathrm{p}$. Ioo) d'ot̀ un fort coefficient d'extinction $\mathrm{E} \mathrm{i}_{1 \mathrm{~cm}}^{1 \mathrm{mg} / \mathrm{ml}}=2,09$ 
à $280 \mathrm{~m} \mu$ (LISSITZKY, RoLLAND et LASRY (I960). Son pouvoir rotatoire $(\alpha) \underset{\mathrm{D}}{25}=$ - $60 \pm 2^{\circ}$ d'après Gordon et SemmetT (I953) ne varie pas entre pH 6,8 et 9,7. Elle présente un minimum de solubilité entre $\mathrm{pH}_{4}$, I et $4,8(0,2$ p. Ioo dans tune solution de $\mathrm{NaCl} 0,05$ à $\mathrm{O}, \mathrm{I} \mathrm{M}$ ) et ceci la rapproche d'une globuline mais elle est insoluble en solution saline concentrée ( $\mathrm{NaCl} 5 \mathrm{p}$. IOo) (Gordon et Semmetr, I953).

TABLEAU 3

Méthodes de préparation de l' $\alpha$-lactalbulmine du lait de vache

10) Selon Gordon, SFMmet et Zifgler (1954)

Lait écrémé

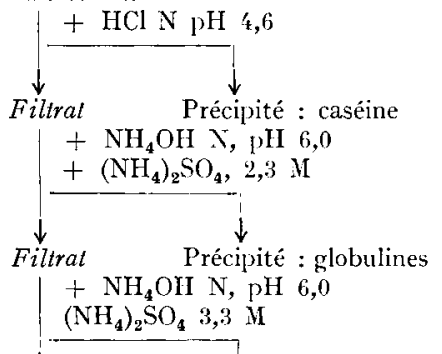

$\stackrel{\downarrow}{\downarrow} \quad \stackrel{\downarrow}{\downarrow}$ Priltrat

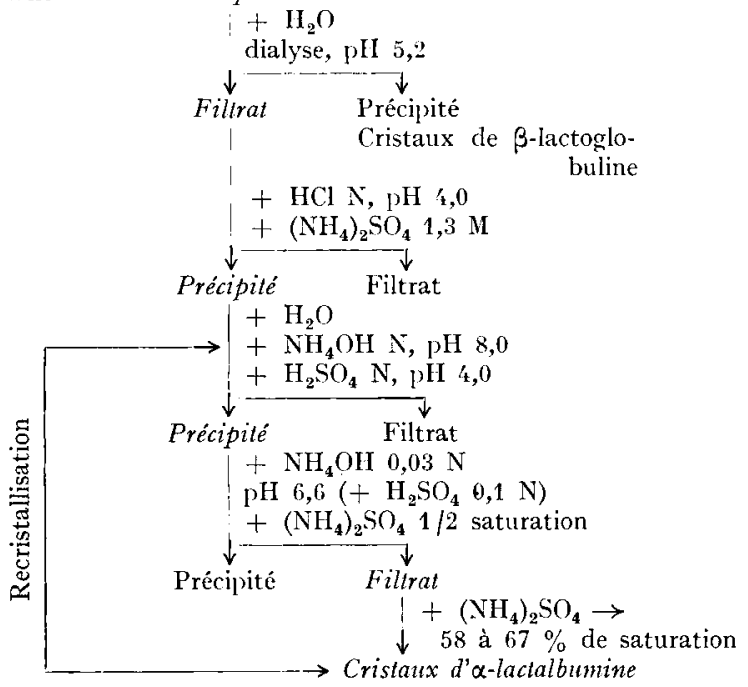

$\left.2^{\circ}\right)$ Selon Aschaffenburg et Drewry (1957)a

Lail entier

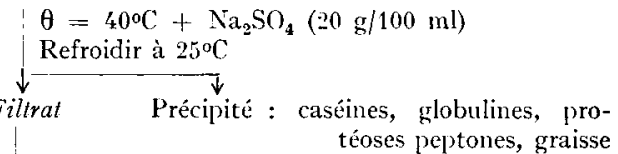

$+1 \mathrm{ml} \mathrm{HCl}$ concentré pour $100 \mathrm{ml}$

Filtrat Précipité

B-Iactoglobuline $\quad+\mathrm{H}_{2} \mathrm{O}$ et $\mathrm{NH}_{4} \mathrm{OH}$

$\underset{\text { Précipité }}{\downarrow} \underset{\text { Filtrat }}{\downarrow}$ : $\beta$-lactoglobu-

Préctpité Filtrat : $\beta$-lactoglobu-
line résiduelle

+ $\mathrm{NH}_{4} \mathrm{OH}$ dilué

$+\mathrm{HCl} \rightarrow{ }_{p} \mathrm{H}_{4}, 0$ et centrifugation

$+\left(\mathrm{NH}_{4}\right)_{2} \mathrm{SO}_{4} 11,5 \mathrm{~g} / 100 \mathrm{ml}$

Précipilé Filtrat : sérum albumine

$+\mathrm{NH}_{4} \mathrm{OH}$ dilué, $\rightarrow \mathrm{pH} \mathrm{i}, 6$

$+\left(\mathrm{NH}_{4}\right)_{2} \mathrm{SO}_{4} \rightarrow 1 / 2$ saturation

Précipité $\quad \stackrel{\downarrow}{\downarrow}$

$+\left(\mathrm{NH}_{4}\right)_{2} \mathrm{SO}_{4} \rightarrow$ $\sim 0,7$ de saturation et concentration de la solution par évaporation

Cristaux $d$ ' $\alpha$-lactalbumine (lavés par $\left(\mathrm{NH}_{4}\right)_{2} \mathrm{SO}_{4}$ à 0,7 de saturation)

$$
\text { 123. - Dosage }
$$

La méthode d'Aschaffenburg et DREwRy (I959) ne détermine que la somme : $\alpha$-lactalbumine + sérum albumine + deux constituants mineurs. Seule la mesure de la surface relative du pic observé par électrophorèse de TISELIUS permet d'évaluer la concentration en $\alpha$-lactalbumine en tenant compte de la remarque de LARSON 
et JENNESS (1955) concernant l'influence des protéines du lactosérum sur la mobilité de $1^{\prime} \alpha$-lactalbumine. Aussi la méthode de dosage immunologique mise au point par LARSON et HaGEMAN (I963) est-elle intéressante. Elle présente les mêmes caractéristiques que celles mises au point par le même auteur pour la $\beta$-lactoglobuline (cf. § II32).

\section{I24. - Conclusion}

L' $\alpha$-Lactalbumine, par son faible poids moléculaire (I6 ooo d'après GoRdon et ZIEGLER, I955 et WETLAUFER, I96r) et sa facilité de préparation sous forme cristalline, semble une protéine intéressante pour entreprendre une étude de structure. De part et d'autre du point isoélectrique, KLostergaArd et Pasternak (I957) ont observé par électrophorèse de Tiseirus une certaine hétérogénéité de l'a-lactalbumine cristallisée dépendant du tampon utilisé et de la concentration en protéines.

\section{I3. - LA SÉRUM ALBUMINE}

Elle ne représente qu'une faible proportion, $4,7 \mathrm{p}$. Ioo, des protéines du lactosérum (tabl. I) et elle a les mêmes propriétés que la sérum albumine du sang (tabl. 4) dont elle ne diffère que par son comportement électrophorétique. Sa mobilité électrophorétique à $\mathrm{pH} 8,4$ est légèrement plus forte et elle montre,

TABLEAU 4

Propriétés comparées de la sérum albumine préparée à partir du sang et du lait de vache

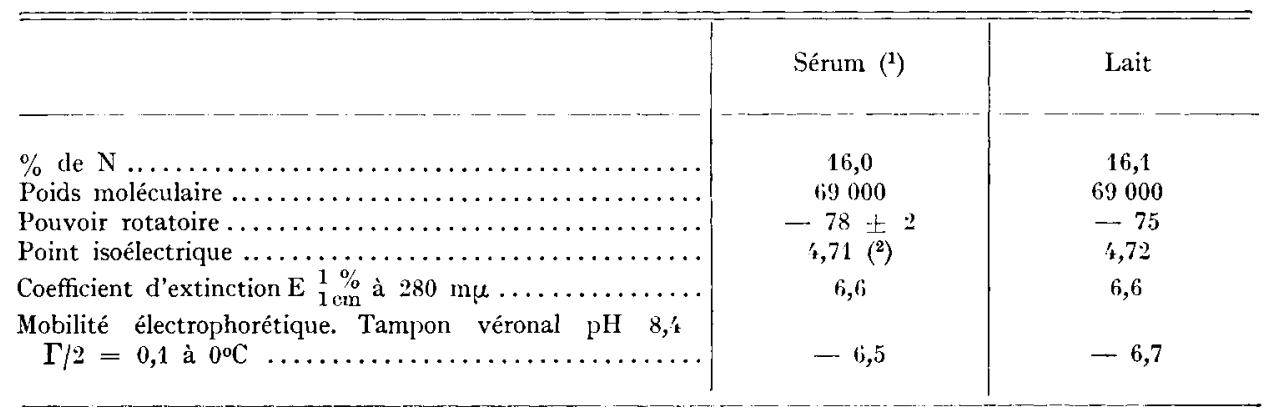

(1) D'après Conn E. J., Hughes W. C. Jr et Weare J. H., 1947. J. am. chem. Soc., 69, 1753.

(2) D'après Longswortir L. G., et JaCoBsen C. F., 1949. J.phys. and coll. Chem., 53, 126.

en tampon acétate $\mathrm{pH} 4,0 \Gamma / 2=0,02$, une hétérogénéité plus marquée que la sérum albumine du sang d'après Polis, SHMUkL ER et CUSTER (I950). Coulson et STEVEns (I950) ont trouvé par contre une identité complète entre les deux protéines en ce qui concerne leurs propriétés antigéniques.

\section{I31. - Séparation}

Polis, SHMukLet et CUSTER (1950) ont appliqué au lait la méthode employée pour séparer la sérum albumine du sang qui consiste à effectuer des fractionnements répétés des protéines solubles par le sulfate d'ammonium (2,4 à 3,4 M) à différents 
$\mathrm{pH}$ puis par l'alcool (Io à $40 \mathrm{p}$. IOO) à basse température. La cristallisation est amorcée par addition finale de sulfate d'ammonium en présence de caprylate.

\section{2. - Identification}

La sérum albumine correspond au pic n⿳0 7 observé par LARSON et ROLLERI (I955)

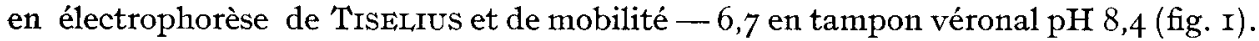
Quelques propriétés ont été rassemblées dans le tableau 4. Elle correspond au composant $\gamma$ de PEDERSEN (I936) de constante de sédimentation $\mathrm{S}_{20}=7, \mathrm{I}$.

$$
\text { I33. - Dosage }
$$

Il n'existe pas de méthode de dosage spécifique et sa concentration ne nous est connue que par électrophorèse selon Tiserius (tabl. I).

\section{II. - LES IMMUNO-GLOBULINES}

D'après RowLAND (I938)a, les globulines du lait correspondent aux protéines du lactosérum qui sont précipitées par le sulfate de magnésium saturé. Comme les globulines du sérum sanguin, elles ont été fractionnées par dialyse en euglobulines et pseudoglobulines. Elles sont constituées essentiellement d'immuno-globulines mises facilement en évidence par leur propriété de réagir avec une substance antigénique bien définie.

$$
\text { 21. - Séparation }
$$

La méthode de séparation des globulines du sérum sanguin a été appliquée par E. L. Smith (I946) au lait. Elle consiste essentiellement à effectuer une précipitation fractionnée des protéines solubles du lait par le sulfate d'ammonium en ne retenant que celles solubles entre 30 et $40 \mathrm{p}$. roo de solution saturée de sulfate d'ammonium. Après dialyse contre l'eau distillée on sépare les euglobulines insolubles (environ I Io $\mathrm{mg} / 1$ de lait écrémé) des pseudoglobulines solubles (environ $60 \mathrm{mg} / \mathrm{l}$ de lait écrémé).

Les euglobulines et pseudoglobulines obtenues sont homogènes par électrophorèse en phase liquide, mais ne sont pas homogènes par ultracentrifugation. KenYon, ANDERSON et Jenness (I959) ont proposé 1'emploi du rivanol (2 ethoxy6,9-diaminoacridine lactate) mais sans réussir à préparer des produits qui soient homogènes par électrophorèse.

\section{2. - Identification}

Les immuno-globulines sont caractérisées par leur faible mobilité électrophorétique en tampon véronal $\mathrm{pH} 8,6 \mathrm{\Gamma} / 2=0, \mathrm{I}, \mu=-\mathrm{I}, 8$ pour les euglobulines et $\mu=-2,0$ pour les pseudoglobulines (MURTHY et WHITNEY, I958). Elles ne contiennent pas de phosphore mais des sucres : 2,5 à 2,9 p. Ioo d'hexose et I,3 p. roo d'hexosa- 
mine (Sмrт́th, I946). 76 à 90 p. Ioo des immuno-globulines sédimentent en un pic de coefficient de sédimentation $\mathrm{S}_{20}=7$ (P. M. I 80 ooo), les autres immuno-globulines sédimentent en deux pics $\left(S_{20}=\right.$ Io et $\left.S_{20}=20\right)$. Elles peuvent être identifiées en mettant à profit leur propriété de réagir comme anticorps avec un certain antigène, réaction spécifique qui peut se traduire par une précipitation, une agglutination, la fixation du complément, etc.

\section{3. - Dosage}

D'après la méthode d'ASchafFENBURG et DREWRy (I959) la teneur en globulines est obtenue en retranchant des protéines non caséines, les protéoses peptones et les albumines. Cela revient à faire une différence entre deux chiffres élevés ce qui réduit considérablement la précision avec laquelle la teneur en globulines du lait peut être connue. La méthode de RowLAND (I938) $b$ conduit à une détermination directe des globulines, les chiffres que cet auteur obtient sont manifestement trop élevés quand on les compare à ceux obtenus par électrophorèse (AschaffeninuRG et DREWRY, I959).

A l'aide de diverses réactions immunologiques il est possible de déterminer la présence de certaines immuno-globulines spécifiques et même de les doser. Lorsque les animaux sont atteints de Brucellose, il suffit de mélanger une solution d'antigènes coloré et le lait : au bout d'un certain temps les anticorps contenus dans le lait agglutinent 1'antigène qui remonte à la surface sous forme d'un disque coloré ("Ring test "). Certaines substances du lait appelées lacténines exercent vis-à-vis de plusieurs microorganismes tels que Str. cremoris, Str. lactis ou Str. pyogenes une action inhibitrice. Certaines de ces substances sont constituées par des anticorps ou agglutinines présents dans le lait. La concentration du lait en agglutinines de ce type est évaluée en déterminant la dilution maximum du lait qui produit encore une agglutination ou une inhibition de la croissance de l'organisme-test (PorTmanN et Auclatr, I959)a.

La détermination de la concentration en anticorps conduit à des mesures relatives et ne donne pas habituellement la quantité en $\mathrm{mg}$ d'anticorps présents. La concentration est exprimée le plus souvent en effet par une dilution limite au-delà de laquelle la réaction spécifique ne se produit plus, elle dépend assez largement du type de la réaction spécifique employée.

Le colostrum, qui correspond à la secrétion des tout premiers jours suivants la mise bas, est très concentré en protéines ( 4 fois plus que le lait normal) et près de la moitié de ces protéines sont constituées par des anticorps ou immuno-globulines. Cette concentration élevée en anticorps fait du colostrum une source de choix pour les préparer. Récemment Montreuil et al. (1963) ont de nouveau mis à profit cette propriété pour fractionner et étudier les diverses immuno-globulines. Ces anticorps jouent un rôle important dans l'immunité qu'acquiert le veau nouveau-né car, contrairement à d'autres espèces animales, les anticorps de la mère ne traversent pas le placenta. Les immuno-globulines ingérées par le jeune animal sont rapidement absorbées par les parois du tube digestif. Cette absorption est facilitée par la présence d'un inhibiteur de la trypsine contenu dans le colostrum qui évite la protéolyse de ces anticorps avant leur absorption (LASKOwsKI et LAskowski, I95I). 


\section{IES PROTÉOSES PEP'TONES}

Les protéoses peptones ont été définies par Rowland (1937) comme les protéines du lactosérum non précipitées à $\mathrm{pH} 4,6$ après chauffage à $95^{\circ} \mathrm{C}$ pendant $30 \mathrm{mn}$ mais précipitées par l'acide trichloracétique à Io p. Ioo. Filles ont été appelées ainsi en raison de leur solubilité dans l'acide trichloracétique à $4 \mathrm{p}$. Ioo comme le sont les premiers produits de dégradation des protéines. De nombreux travaux en particulier ceux de ROWLAND (I937), LARSON et ROLLERI (I955), ASCHAFFENBURG et DREWRY (I959) ont montré qu'elles préexistent dans le lait non chauffé et que par suite elles ne semblent pas être le résultat de dégradation d'autres protéines. Elles constituent un groupe complexe et malgré un certain nombre de tentatives il n'a pas été possible de préparer des fractions homogènes. Toutes les protéoses peptones préparées possèdent en commun les propriétés d'être des glycoprotéines et d'être sensibles à l'action de la présure (BRUNNER et THOMPson, Ig6I). Nous avons réuni dans ce chapitre les différentes préparations suivantes : protéoses peptones d'après RowLAND (I938), protéose $\sigma$ d'après AschaFFENBURG (I946), constituant 5 d'après JenNess (I959) et la fraction protéique mineure de Weinstein, Duncan et 'Trout (I95I).

\section{I. - Séparation}

La méthode de Rowland (I938)a, reprise par BRUNnER et Thompson (I96I) consiste à précipiter la caséine à $\mathrm{pH} 4,6$ après chauffage du lait à $95^{\circ} \mathrm{C}$ pendant $30 \mathrm{mn}$. Le filtrat est dialysé et lyophilisé.

La protéose $\sigma$ préparée selon AschafFanburg (I946) représente les protéoses peptones selon Rowland insolubles dans le sulfate d'ammonium à demi saturation. La préparation de la fraction protéique mineure de WEINSTEIN, DUNCAN et TrouT (I95I) est assez analogue à celle de la protéose $\sigma$ mais la caséine est éliminée sous forme de paracaséinate de calcium insoluble après action de la présure. La préparation du constituant 5 est résumée dans le tableau 5 .

Aucune de ces préparations ne sont homogènes par ultracentrifugation ou par électrophorèse (tab1. 6).

\section{2. - Identification}

Les analyses faites par Brunner et Thompson (I96r) et Thompson et BRUNNER (I959) sont assez significatives de ce groupe de glycoprotéines et elles sont indiquées dans le tableau 6 . Les protéoses peptones étudiées contiennent toutes du phosphore, des sucres et pour certaines d'entre elles on a trouvé de l'acide sialique en proportions analogues à celles observées pour les glycoprotéines du sang, ce qui fait penser à une commune origine. Un certain pourcentage, non négligeable, de ces protéines sont solubles dans l'acide trichloracétique à i2 $\mathrm{p}$. Ioo et le pourcentage très élevé obtenu avec la fraction protéique mineure s'explique si l'on considère qu'elle doit être fortement contaminée par les produits de dégradation des caséines par la présure solubles dans 1'acide trichloracétique à I2 p. IOo. Après action de la présure, la proportion de protéine soluble dans l'acide trichloracétique à $\mathrm{I} 2 \mathrm{p}$. Ioo augmente pour chacune des fractions de protéoses peptones préparées (BRUNNER et THOMP- 


\section{TABLEAU 5}

Préparation du constituant 5 à partir du lait de vache normal d'après Jenness (I959) adaptée par BRUNNER et Thompson (196r)

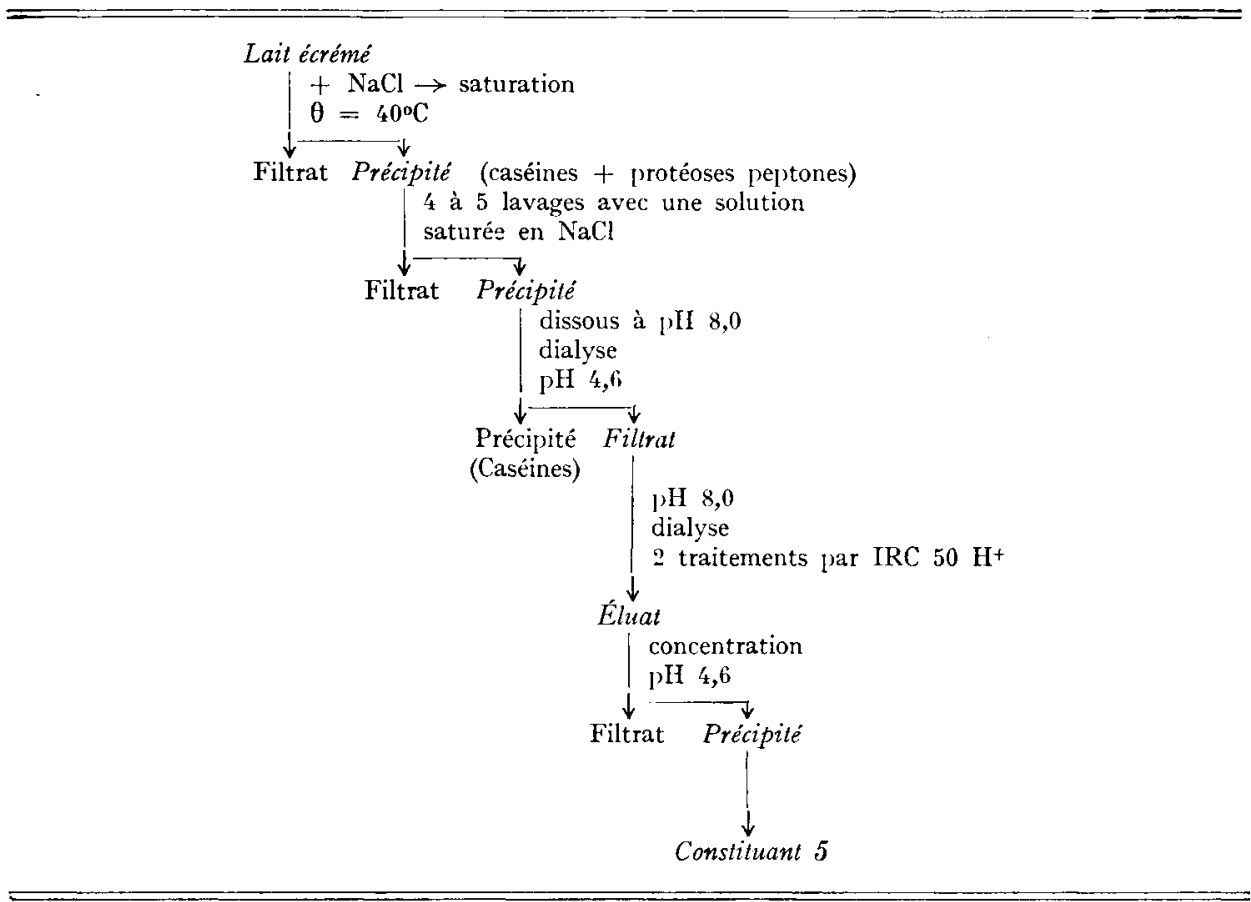

\section{TABLEAU 6}

Composition des différentes protéoses-peptones du lait de vache normal ( $\left.{ }^{1}\right)$

\begin{tabular}{|c|c|c|c|c|c|c|c|}
\hline & $\begin{array}{l}N \\
(\%)\end{array}$ & $\begin{array}{c}\mathrm{P} \\
(\%)\end{array}$ & $\begin{array}{c}\text { Hexose } \\
(\%)\end{array}$ & $\begin{array}{c}\text { Acide } \\
\text { sialique } \\
(\%)\end{array}$ & $\begin{array}{c}N \text { soluble } \\
\text { dans } \\
\text { TCA 12\% } \% \\
(\%)\end{array}$ & $\begin{array}{c}S_{20} \\
\text { U. Sved. }\end{array}$ & $\begin{array}{c}\left.\mu{ }^{2}\right) \\
\mathrm{cm}^{2} \mathrm{~s}^{-1} \mathrm{v}^{-1} \times 10^{-5}\end{array}$ \\
\hline $\begin{array}{c}\text { Protéoses peptones.... } \\
\text { (RowLAND) } \ldots \ldots \ldots \ldots \\
\text { Protéose } \sigma \quad \ldots \ldots \ldots \ldots \\
\text { Constituant } 5 \ldots \ldots \ldots \\
\text { Fraction } \quad \text { protéique } \\
\text { mineure } \ldots \ldots \ldots \ldots \ldots\end{array}$ & $\begin{array}{l}13,7-13,9 \\
13,7-13,9 \\
12,6 \\
10,2-10,4\end{array}$ & $\begin{array}{l}1,1 \\
0,88 \\
1,5 \\
0,6\end{array}$ & $\begin{array}{l}2,9-4,3 \\
2,8 \\
0,92 \\
3,46-6,94\end{array}$ & 3,6 & $\begin{array}{r}19,36 \\
3,98 \\
6,67 \\
\\
41,24\end{array}$ & $\begin{array}{l}2,64-0,77 \\
2,86-0,83 \\
5,88-0,88 \\
\\
2,83-0,84\end{array}$ & $\begin{array}{c}6,3-3,5-2,0 \\
5,8-3,9-2,0 \\
7,2-5,4-4,4-2,8 \\
\\
5,3-4,5-3,1\end{array}$ \\
\hline
\end{tabular}

(1) D'après Brunner et Thompson (1961) et Thompson et Brunner (1959).

(2) Mobilité électrophorique (branche descendante) en tampon véronal $\mathrm{pH} 8,6$, le constituant le plus important en quantité est indiqué en chiffres italiques. 
son, I96I). Cette augmentation est de $13 \mathrm{p}$. Ioo de la protéine initiale pour la protéose peptone, de I p. Ioo pour la protéose $\sigma$, de $0,6 \mathrm{p}$. Ioo pour le constituant 5 et $5,5 \mathrm{p}$. Ioo pour la fraction protéique mineure. L'examen électrophorétique révèle la présence dans ces préparations d'un constituant commun de mobilité 3,5 à 4,5 selon les fractions (tabl. 6) et qui correspond sensiblement au pic no 5 observé au cours de l'électrophorèse du lactosérum (fig. I) d'où le nom de constituant 5 donné à la préparation correspondante par JENNESS (I959). L'ultracentrifugation montre en outre l'existence de deux séries de constituants, l'un de coefficient de sédimentation $\mathrm{S}_{20}=0,8$ et l'autre de $\mathrm{S}_{20}=2,8$. La protéose $\sigma$ d'AschafrenBuRG (I946) est douée de propriétés tensio-actives. Enfin AschaFFENBURG et DREWRY (I959) ont signalé que les protéoses peptones, après électrophorèse sur papier, se coloraient en jaune avec le bleu de bromophénol, mais elles sont cependant difficiles à déceler.

\section{3. - Dosage}

En se basant sur ce dernier caractère de coloration, les mêmes auteurs ont indiqué que le procédé de RowlAND (I938)a ne conduisait pas à une séparation nette des protéoses peptones. La méthode de RowLAND consistait à doser l'azote soluble à pH 4,7 après chauffage à l'ébullition 5-Io mn et à déduire l'azote soluble dans l'acide trichloracétique à I2 p. IOO (ou N.P.N.). Les résultats obtenus par cette méthode étaient toujours plus élevés que ceux obtenus par électrophorèse de LARson et RoLLERI (r955) où les protéoses peptones sont représentées par les constituants 3, 5 et 8 (fig. I). D'après AschafFenburg et Drewry (r959) les protéoses peptones précipitent quand on ajoute $\mathrm{I} 2 \mathrm{~g}$ de sulfate de sodium à roo $\mathrm{ml}$ de filtrat de lait de vache précipité à $\mathrm{pH} 4,6$. De l'azote non caséine on déduit l'azote du surnageant pour calculer l'azote des protéoses peptones précipitées. Cette méthode a le mérite de fournir des résultats proches de l'analyse électrophorétique. En effet si AscHAFFENBURG et DREWRY (I959) identifient 6 protéoses peptones, l'une correspondrait au constituant 5 (fig. I) et les 5 autres au constituant 3 , la somme des constituants 3 et 5 se rapproche des quantités de protéoses peptones déterminées par AschafFEnBURG et DREWRY (I959) (tabl. I).

\section{IV - LES PROTÉINES MINEURES}

Nous avons groupé sous ce terme toutes les autres protéines du lait dont la concentration n'est pas suffisante pour être décelée par électrophorèse selon TiSEI,IUS en tampon véronal $\mathrm{pH} 8,6 \Gamma / 2=0$,I. Elles comprennent essentiellement la protéine rouge, la lactolline, les protéines de la membrane des globules gras et les enzymes du lait.

\section{I. - La protéine rouge ou lactotransferrine}

Après les premières tentatives en vue de séparer du lait une protéine rouge, GRoves (I960) réussit à préparer celle-ci dans un excellent état de pureté en utilisant une propriété particulière : l'adsorption sur le précipité de caséine au point isoélectrique. 
4II. - Séparation.

La technique employée par Groves (I960) a été résumée dans le tableau 7 ; cette séparation se termine par une chromatographie sur échangeur d'ions (D.E.A.E. cellulose). Comme d'après GoRdON, ZIEGLER et BASCH (I962) il semble que la protéine rouge existe également dans le lait sous une forme incolore non combinée à du fer, ces derniers auteurs ont suggéré d'ajouter au lait du fer pour augmenter les rendements en protéine rouge.

\section{2. - Identification.}

La préparation de protéine rouge ou lactotransferrine selon Groves (I960) est homogène à l'électrophorèse selon TrSELIUS, son point isoélectrique est de 7,8 $(\Gamma / 2=0, I)$ et ne donne qu'un seul pic par ultracentrifugation en tampon phosphate $\mathrm{pH} 7\left(\mathrm{~S}_{20}=5,2\right)$. Groves a déterminé un poids moléculaire de 86 Ioo. La protéine rouge contient deux atomes de $\mathrm{Fe}$ par molécule et présente un maximum assez large d'absorption vers $470 \mathrm{~m} \mu$ à $\mathrm{pH}$ neutre. Il est possible de dissocier à $\mathrm{pH}$ acide et d'une manière réversible le complexe Fe-protéine. Elle appartient au groupe des glycoprotéines phosphorées avec une teneur en phosphore de 0,22-0,25 p. IOO, en

\section{TABLEAU 7}

Préparation de la protéine rouge à partir du lait de vache normal d'après GRoves (I960)

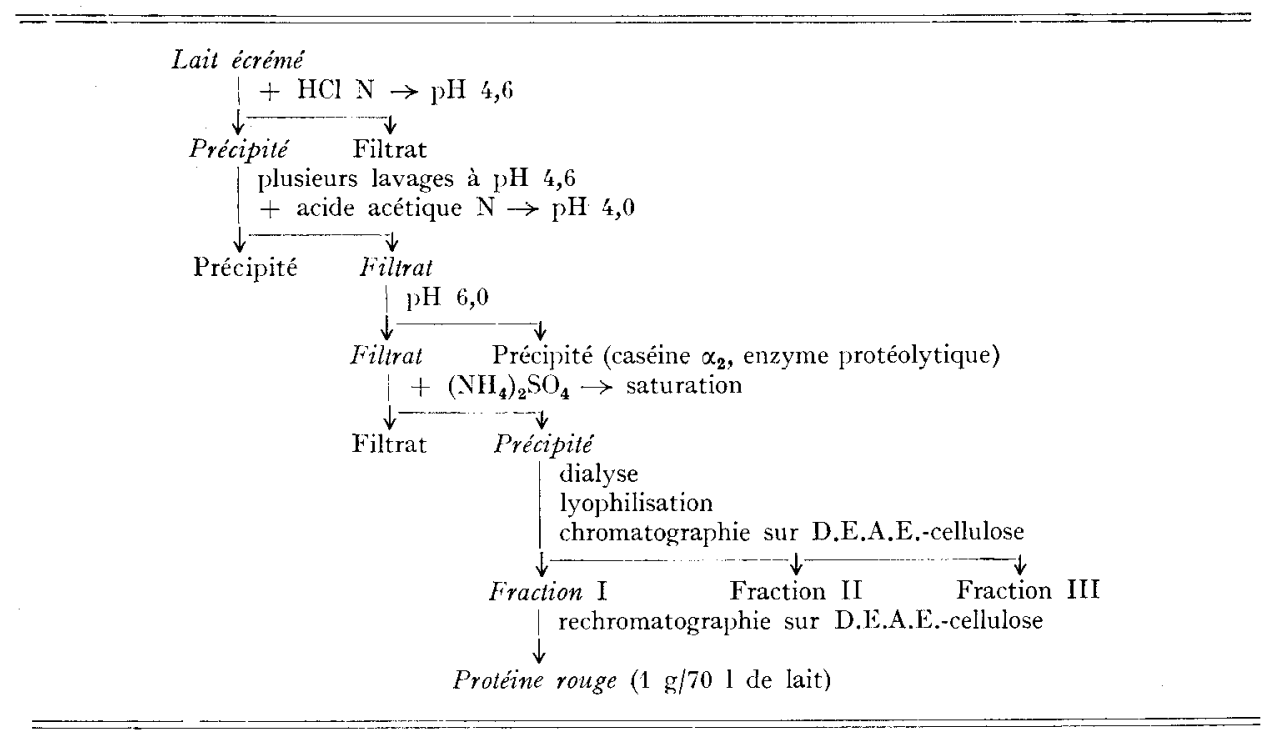

hexose de 4,7 p. Ioo, en hexosamine de 2,3 p. Ioo et en acide sialique de 0,3 p. Ioo. Elle diffère de la transferrine du sang aussi bien par sa composition en acides aminés que par son comportement par chromatographie, électrophorèse et ultracentrifugation (Gordon, Groves et Basch, I963). Blanc, Bujard et Mauron (I963) ont également donné sa composition en acides aminés en la comparant à la lactotransferrine humaine. 
413. - Dosage

Il n'existe pas de dosage spécifique dans le lait. Sous forme de préparation purifiée il est possible de mettre à profit le maximum d'absorption observé de 465 à $470 \mathrm{~m} \mu$. Groves ( 1960 ) a déterminé cependant un coefficient d'extinction assez faible $\mathrm{E}_{\mathrm{l}}^{\mathrm{l} \mathrm{mg} / \mathrm{ml}}=0,05$ à $465 \mathrm{~m} \mu$ et à $\mathrm{pH}$ neutre.

\section{2. - La lactolline}

Comme la protéine rouge, la lactolline est adsorbée sur le précipité de caséine à $\mathrm{pH}$ 4,7. Signalée au début comme la protéine cristallisée par GrovEs (I960), elle n'a été que récemment étudiée (Groves, BAsch et Gordon, I963).

\section{I. - Séparation.}

La technique d'isolement de Groves, BASCh et GoRdon (Ig63) est celle de Groves (I960) pour séparer la protéine rouge (tabl. 7) en y incluant un fractionnement supplémentaire par le sulfate d'ammonium (40 à $60 \mathrm{p}$. Ioo de saturation). Les cristaux recueillis directement après chromatographie sur D.E.A.E.-cellulose (1a lactolline est éluée immédiatement après la protéine rouge) sont dissous à $\mathrm{pH} 5,0$ et recristallisés deux fois après ajustement du $\mathrm{pH}$ à 6,2 et à 8,2 . Le rendement est de 0,6 à $\mathrm{I}, 6 \mathrm{mg}$ de lactolline par litre de lait écrémé. Il est accru en partant du colostrum : $5,9 \mathrm{mg} /$ litre.

\section{2. - Identification.}

Elle présente la propriété de cristalliser facilement à $\mathrm{pH}$ neutre d'où son premier nom (Groves, I960). Elle présente un minimum de solubilité à $\mathrm{pH} 8$ et son point isoélectrique est situé vers $\mathrm{pH} 7$, I. Son poids moléculaire est de $42900 \pm 5000$ $\left\langle\mathrm{S}_{20, \omega}=3,2 \mathrm{I}\right.$ à $\mathrm{pH} 5$, tampon acétate $\left.\Gamma / 2=0, \mathrm{I}\right)$. Elle ne contient pas de méthionine, peu d'alanine et cystine mais une forte proportion d'acides aminés aromatiques.

\section{3. - Dosage.}

Il n'existe pas de dosage spécifique dans le lait. Le coefficient d'extinction à $280 \mathrm{~m} \mu, \mathrm{E}_{1 \mathrm{~lm}}^{\mathrm{lmg} / \mathrm{ml}}=\mathrm{I}, 65$ à $\mathrm{pH} 5$ (GROves, BASch et GoRdon, I963) peut être utilisé pour déterminer la concentration d'une solution de lactolline cristallisée.

\section{3. - Les protéines de la membrane des globules gras}

Quoiqu'elles aient des propriétés assez voisines de celles des protéoses peptones, leurs caractéristiques d'ultracentrifugation, leur propriété de former des complexes avec les lipides (et par suite d'être disposées à la surface des globules gras) nous conduit à les ranger dans une catégorie spéciale.

\section{1. - Séparation.}

Nous avons reporté dans le tableau 8 la méthode de séparation la plus couramment utilisée actuellement : celle d'Herald et Brunver (I957). Morton (I954) a également décrit une méthode conduisant à la séparation d'un complexe lipoprotéique attribué aux microsomes du lait provenant des cellules de la glande mammaire. 


\section{2. - Identification.}

Ce sont des glycoprotéines $(2,69$ à 4,04 p. Ioo d'hexose d'après Brunner et Thompson (I96I) qui contiennent du phosphore (o,68 p. IOo).

Une proportion relativement élevée est soluble dans l'acide trichloracétique à I2 p. Ioo (environ 6 p. IOo) mais elles ne sont pas sensibles à l'action de la présure même après chauffage. Par électrophorèse selon Trselıus elles se montrent constituées par deux fractions, l'une de mobilité $\mu=4,7$ (96,5 p. I0o) et l'autre de mobilité $\mu=2,3$ (3,5 p. Ioo) en tampon véronal $\mathrm{pH} 8,6$. Par ultracentrifugation elles sédimentent sous la forme de deux constituants de coefficient de sédimentation $S_{20}=I_{7}, 6$ et 9,05 en tampon véronal $\mathrm{pH} 8,6 \mathrm{\Gamma} / 2=0, \mathrm{I}$. La valeur très élevée de ces deux coefficients de sédimentation les différencie des protéoses peptones.

TABLEAU 8

Préparation des protéines de la membrane des globules gras à partir du lait de vache normal d'après Herald et Brunner (1957) et Brunner et Thompson (I96I)

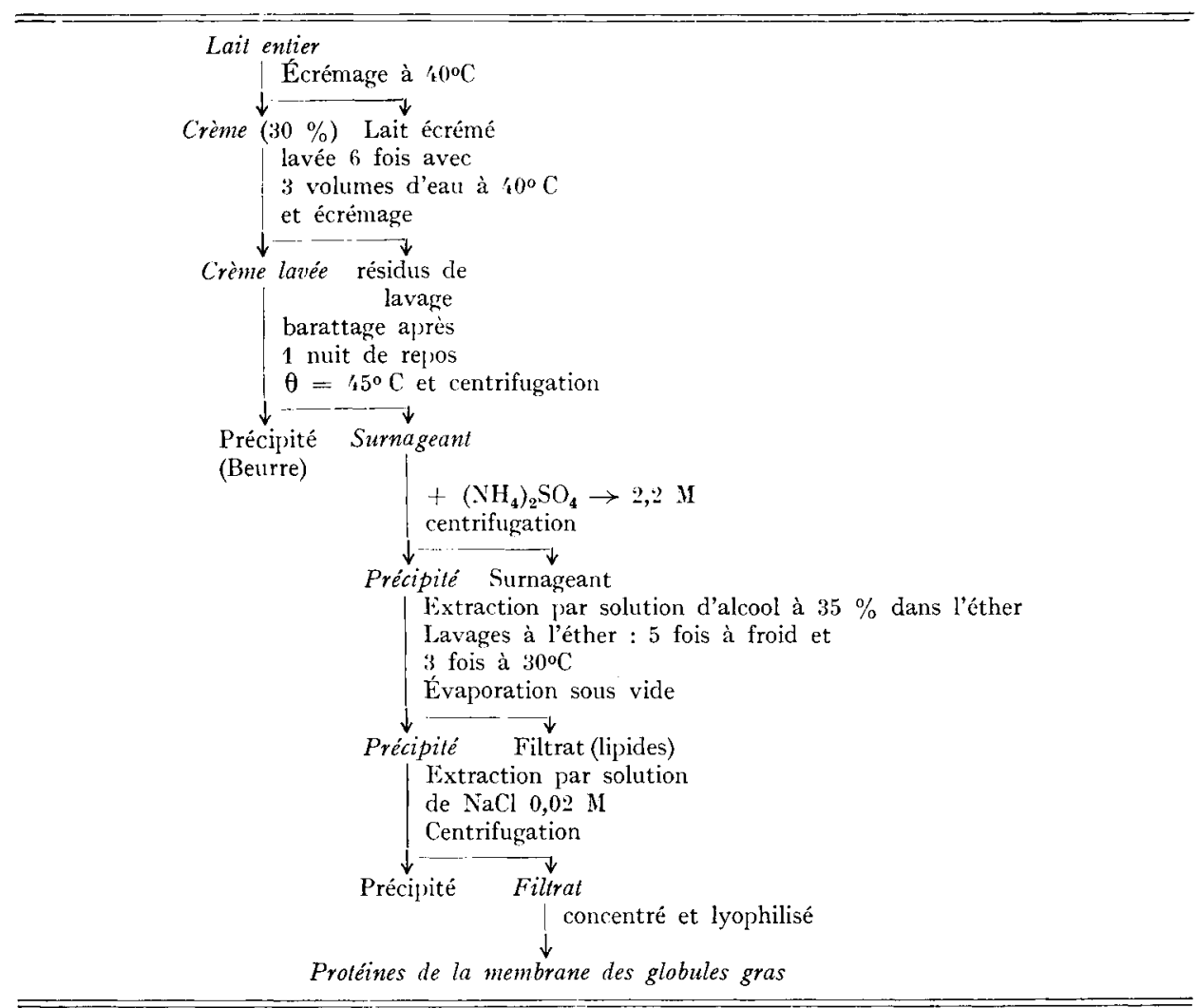

\section{3. - Dosage.}

Il n'existe pas de méthode de dosage de ces protéines. Étant liées aux lipides sous forme de complexe lipoprotéique, elles ne sont pas des constituants normaux du lait. écrémé. 


\section{4. - Les enzymes du lait}

Ils sont nombreux, mais leurs origines sont le plus souvent assez mal définies car elles peuvent être fort différentes : ils peuvent en effet être secrétés par la glande mammaire, ou provenir du plasma sanguin, ou provenir des leucocytes ou encore des bactéries présentes dans le lait.

Cette dernière éventualité est souvent éliminée en utilisant du lait obtenu par traite aseptique de vaches dont la mamelle n'héberge aucun germe microbien. Quelques-uns de ces enzymes ont été préparés à l'état cristallisé. La destruction de certains par la chaleur est utilisée comme test d'une pasteurisation convenable. Étant donné leur faible importance, quantitativement et qualitativement, nous nous contenterons d'en faire ici une revue rapide, inspirée en particulier d'une mise au point faite par WHITNEY (I958) en considérant plus spécialement leur séparation, leur identification et leur dosage. Nous les avons classés dans l'ordre où ils sont le mieux étudiés et connus et en ne retenant que ceux normalement présents dans le lait.

44I. - Le xanthine oxydase.

Son nom provient de sa propriété de transformer la xanthine en acide urique. Préparée sous forme cristallisée par AvIS, BERGEL et BRAY (I955), elle catalyse l'oxydation du diphosphopyridine nucléotide réduit (DPNH) en utilisant différents accepteurs d'électrons : oxygène, bleu de méthylène, cytochrome c etc... Elle est constituée, dans le rapport moléculaire $I / 2 / I, 3-I, 5 / 8$, de protéine-flavine adénine dinucléotide-Mo-Fe pour un poids moléculaire d'environ 300 o0o $\left(\mathrm{S}_{20}=\mathrm{II}, 4\right)$ (AvIS et al., I956). Elle présente une large bande d'absorption à $45^{\circ} \mathrm{m} \mu$ correspondant à sa couleur brun rouge, ainsi que deux autres bandes d'absorption à $350 \mathrm{~m} \mu$ et surtout à $275 \mathrm{~m} \mu$. GreEnbank (1954) a mis au point une méthode de dosage basée sur la réduction du bleu de méthylène par l'hypoxanthine et il a trouvé I6o mg environ de xanthine oxydase par litre de lait. La xanthine oxydase est souvent associée à la membrane des globules gras.

\section{2. - La lactoperoxydase.}

POLIS et SHMUkLER (I953) la préparent à partir du lactosérum présure par précipitation fractionnée à l'aide du sulfate d'ammonium et chromatographie sur colonne de phosphate de calcium. La cristallisation de l'enzyme est obtenue à partir d'une solution 2,2 M de phosphate dipotassique. Elle peut être préparée sous une forme hautement purifiée mais non cristallisée selon un procédé relativement simple d'après MORRISSON, HAMILTON et STOTZ (I957). Il comporte essentiellement plusieurs passages du lactosérum présure sur colonne échangeuse d'ions IRC 50 (X E 64). La lactoperoxydase est identifiée grâce à la bande d'absorption qu'elle possède à 4I2 mu. Le groupement prosthétique est constitué par un hème avec un atome de fer et PoLIs et SHMUKLER (I953) ont déterminé un poids moléculaire de $8 \mathrm{I}$ ooo.

On peut la doser soit en suivant son activité enzymatique par la méthode au gaïacol par exemple de MEALHY (I954) ou bien en déterminant son activité inhibitrice sur la croissance de Str. pyogenes d'après la méthode d'AUCLAIR et Hirsch (I953) d'estimation de la lacténine $\mathrm{L}_{\mathbf{2}}$ dont l'identité avec la lactoperoxydase a 
été démontrée par Portmann et Auclair (I959). D'après les résultats de Polis. et Shmukler (1953) il est possible de calculer la teneur du lait en lactoperoxydase soit environ $30 \mathrm{mg} /$ litre (WHITNEy, I958).

La lactoperoxydase a donné lieu à des études théoriques de la réaction enzymesubstrat, en particulier celles de Chance (I950) et de THEOREL, et al.

\section{3. - La phosphatase alcaline.}

C'est également un constituant normal du lait présent à l'interface sérumglobules gras. MORTON (I953) l'a préparée à partir de la crème : celle-ci est barattée, les lipoprotéines contenues dans le babeurre sont dissociées par traitement avec le butanol et les protéines ainsi séparées des lipides sont fractionnées par le sulfate d'ammonium. MorTon a ainsi obtenu un enzyme hautement purifié mais non cristallisé, homogène à l'électrophorèse et ne possédant qu'une activité de phosphomonoestérase.

Le dosage de la phosphatase dans le lait est pratiqué en utilisant comme substrats: le phénylphosphate disodique (KAy et Graham, I935 et Aschaffenburg et Neave, r939) et le paranitrophényl phosphate, en titrant le phénol libéré par le réactif de Folin et Crocaliteu par exemple, ou le $\beta$-glycérophosphate de soude en déterminant le phosphore libéré (JAcquet et SAINGT, I952).

Le fait qu'elle soit dénaturée plus lentement par la chaleur que ne sont détruits les microorganismes pathogènes non sporulés a été mis à profit pour vérifier la pasteurisation correcte du lait.

D'autres phosphatases ont été signalées dans le lait : une phosphodiestérase, deux pyrophosphatases (Guittoneau, Chevalier et Jarrousse, I944) et deux phosphomonoestérases acides dont l'une serait plus résistante à la destruction par la chaleur que la phosphatase alcaline (JACQUET et SAINGT, I952).

\section{4. - Les lipases du lait.}

Il existe toute une série de lipases naturelles dans le lait capables d'hydrolyser un certain nombre de substrats : beurre, huiles végétales, tributyrine, etc. Certaines de ces lipases sont actives spontanément dans le lait - en particulier celles qui s'adsorbent sur la membrane des globules gras au cours du refroidissement du lait - d'autres ont besoin d'une activation par agitation ou homogénéisation et elles sont le plus souvent associées à la fraction caséine (TARASSUK et FrankEL, I957).

Quelques essais de séparation des lipases ont été tentés par TARAssuK et FranKEL (I957) et HARPER, Gould et BADAMI (I956) sans obtenir de préparations homogènes. D'autres tentatives plus récentes semblent avoir été plus fructueuses. MoN'TGOMERY et FORSTER (I96I) ont purifié l'estérase B en l'adsorbant sur l'hydroxyde de magnésium $\mathrm{Mg}(\mathrm{OH})_{2}$. Chandan et Shahani ( $\mathrm{I} 963$ ) ont légèrement modifié le procédé de DESNUELLE (I96I) et l'ont appliqué aux boues d'écrémeuses qu'ils ont extraites à l'acétone, à l'eau, puis après précipitation fractionnée par le sulfate d'ammonium et chromatographie sur Sephadex G 50 ils ont obtenu une préparation homogène à l'électrophorèse sur gel d'amidon d'un poids moléculaire d'environ 7 ooo. Cet enzyme purifié hydrolyse les graisses du lait et la tributyrine.

Le dosage des lipases se fait soit d'après la mesure de la vitesse d'hydrolyse d'esters de référence : tween 20 , tributyrine, butyrate de méthyl, phényl propionate, etc. au $\mathrm{pH}$ stat ou en mesurant le $\mathrm{CO}_{2}$ dégagé à partir d'un tampon bicar- 
bonate au Warburg; soit d'après le dosage des acides gras libérés séparés au préalable sur colonne de silicagel (Harper, Schwartz et EL Hagarawy, I956). La teneur en lipase est exprimée par FRANKEr, et TARASsuK (I956) en unités arbitraires d'après la mesure de la quantité de soude nécessaire pour neutraliser l'acide formé lors de 1'hydrolyse par la lipase de la liaison ester, ou encore en micromoles d'acides gras libérés/Ioo $\mathrm{ml}$ de mélange réagissant $/ \mathrm{h} / \mathrm{mg}$ de protéine comme il est recommandé dans le Rapport de la Commission sur les Enzymes (I96I).

On a distingué 3 lipases alcalines ( $\mathrm{pH}$ optimum 7 à 7,9$)$ et 4 lipases acides $(\mathrm{pH}$ optimum 5,4 à 6,3). L'une des lipases alcalines appartient d'après FORSTER, BENDIXEN et MonTGOMERy (I959) au groupe des estérases B qui hydrolysent à la fois les esters aromatiques et aliphatiques et sont inhibés par les composés organophosphoriques. Les mêmes auteurs distinguent également dans le lait une activité estérase A, spécifique des esters aromatiques, non inhibée par les composés organophosphoriques et probablement une activité estérase $\mathrm{C}$ spécifique des esters de choline et inhibée par la physostigmine. La teneur en estérase A augmente beaucoup dans les laits de mammites (MARQUARD'T et Forster, I962).

Les lipases jouent un rôle important dans la lipolyse spontanée des matières grasses (goût de rance) du lait et des produits laitiers (beurre, fromages) (BACHMAN, I959).

Plusieurs revues générales ont été publiées concernant les lipases du lait; la plus récente est celle de Chandan et ShaHaNi (I964).

445. - Amylase.

Le lait possède la propriété d'hydrolyser l'amidon. GuY et JENnEss (I958) ont obtenu une préparation fortement concentrée par précipitation du lactosérum par le sulfate d'ammonium à 43 p. Ioo de saturation. Il semble que cette préparation ait un seul $\mathrm{pH}$ optimum d'activité à 7,4 .

L'activité de cette amylase est mesurée en suivant la variation de viscosité de l'amidon, la quantité de sucres réducteurs libérés ou la quantité de l'amidon non hydrolysé par le réactif à l'iode.

446. - Protéase.

WARNER et Poris (I945) ont montré que presque toute l'activité protéolytique du lait était précipitée avec la caséine. Ils ont obtenu une préparation enrichie I50 fois en cet enzyme par précipitation à $\mathrm{pH} 4,5$ d'une solution de caséine protéolysée et dialysée et fractionnement du filtrat par le sulfate d'ammonium.

Cet enzyme de propriétés voisines de la trypsine a un optimum d'activité à $\mathrm{pH} \mathrm{9,2}$ et résiste à l'action de la chaleur. Par fractionnement de la caséine à l'alcool et à l'urée, il se trouve dans la fraction caséine $\alpha$ (HIPP et al., I952) et il peut en être éliminé par précipitation fractionnée à l'alcool à $\mathrm{pH} 6,0$.

\section{7. - Catalase.}

Il semble qu'elle soit un enzyme naturel du lait d'après REID (I93I) mais il y a toujours une forte proportionnalité entre la quantité de catalase présente dans le lait et le nombre de bactéries ou de leucocytes présents. Aucun essai de séparation n'a été entrepris.

D'autres enzymes ont été signalés dans le lait sans que leur origine soit bien établie telle que l'aldolase qui hydrolyse le fructose I-6-diphosphate. Polis et SHMu- 
KLER (I950) ont montré qu'elle était concentrée dans la crème et ils ont amorcé un début de fractionnement par les sels neutres.

Enfin Dills et NELson (I942) ont séparé du lactosérum une protéine contenant 0,19 p. Ioo de cuivre non dialysable à $\mathrm{pH} 6,5$ ou cérumoplasmine. Elle serait à 'origine du cuivre présent dans le lait à l'état non-dialysable.

Reçu pour publication en février 1964 .

\section{SUMMARY}

A review on the separation, identification and evaluation of whey proteins of cow's milk.

Introduction

CONTENTS

I. Albumins

I $\beta$-lactoglobulin

I $\alpha$-lactalbumin

I3 serum albumin

II. Immune globulins

III. Proteose peptones

IV. Minor proteins

$4 \mathrm{I}$ Red protein or lactotransferrine

42 Lactollin

43 Fat globules membrane proteins

44 Milk enzymes

441 Xanthine oxydase

$44^{2}$ Lactoperoxydase

443 Alkaline phosphatase

444 Milk lipases

445 Amylase

446 Protease

447 Catalase

References

\section{RÉFÉRENCES BIBLIOGRAPHIQUES}

Aschaffendurg R., 1946. Surface activity and proteins of milk. J. Dairy Res., 14, 316-329.

Aschaffenburg R., Drewry J., 1955. Occurrence of different beta-lactoglobulins in cow's milk. Nature 176, $218-219$.

ASChafFEnBURG R., DREWRy J., I957a. Improved method for the preparation of crystalline $\beta$-lactoglobulin and $\alpha$-lactalbumin from cow's milk. Biochem. J., 65, 273-277.

Aschaffenburg R., Drewry J., I957 $b$. Genetics of the $\beta$-lactoglobulins of cow's milk. Nature, 180, 376-378.

Aschaffenburg R., Drewry J., I959. New procedure for the routine determination of the various non casein proteins of milk. $X V^{\mathrm{e}}$ Cong. intern. Lait., 3 , sect. 5 , I631-1637.

AscinffFenburg R., Neave F. K., 1939. A rapid phosphatase test. J. Dairy Res., 10, 485-497.

Auclair J. E., Hirsch A., 1953. The inhibition of microorganisms by raw milk. J. Dairy Res., 20, 45-49.

Avis P. G., Bercel F., BraY R. C., I955. Cellular constituents. The chemistry of xanthine oxydase. Part I. The preparation of a crystalline xanthine oxydase from cow's milk. J. Chem. Soc., 77, I 100-I I05,

Avis P. G., Bercet F., Bray R. C., James W. F., Shooter K. V., 1956. Cellular constituents. The chemistry of xanthine oxydase. Part. II. The homogeneity of crystalline metalloflavoprotein fractions. $J$. Chem. Soc., 78, 1212-1219. 
Bacimann M., 1959. Der Einfluss von Milch mit Erhöhter Lipaseaktivität auf die Käsereifung. $X V$ e Congr. intern. Lait., 2, 7 I 2-715.

BELL K., I962. One dimensional starch-gel electrophoresis of Bovine skim milk. Nature, 185, $705-706$.

Blanc B., Bujard E., MaUron J., ig6 3 . The amino acid composition of human and bovine lactotransferrine Experientia, 19, 299-301.

BRUnNer J. R., Thompson M. P., 196r. Characteristics of several minor-protein fractions isolated from Bovine milk. J. Dairy Sci., 44, 1 224-1 237.

Cannan R. K., Palmer A. H., Kibrick A. C., I942, The hydrogen ion dissociation curve of $\beta$-lactoglobulin. J. Biol. Chem., 142, $803-822$.

CEClL R, OGSTON A. G., I 949. The sedimentation constant, diffusion constant and molecular weight of lactoglobulin. Biochem. J., 44, 33.

Chance B., I950. The properties of the enzyme-substrate compounds of lactoperoxydase. J.am. chem. Soc., 72, $1577^{-1} 583$.

Chandan R. C., Shahani K. M., i963. Purification and characterization of milk lipase. I. Purification. J. Dairy Sci., 46, 275-283.

Chandan R. C., Shahani K. Y., I964. Milk Lipases. A Review, J. Dairy Sci., 47, 471-480.

Coulson E. J., Stevens H., I950. The serological relationship of bovine whey albumin to serum albumin. J. Biol. Chem., 187, 355-363.

Crowther C., Raistrick H., igi6. A comparative study of the proteins of the colostrum and milk of the cow and their relation to serum proteins. Biochem. $J ., 10,434^{-4} 5^{1}$.

Dautrevaux YI., I963. Isolement de l' $\alpha$-lactalbumine du lait de vache. Ann. Biol. Anim. Bioch. Biophys., $3, n^{\circ}$ hors série, $125^{-127}$.

Desndelle P., ז961. Pancreatic lipase. Adr. Enzymology, 23, I29.

Dills W. L., Nelson J. M., ig42. Isolation of a copper bearing protein from cow's milk. J. Am. chem Soc., 64, 1616.

Forster T. L., Bendixen H. A., Montgomery M. W., i959. Some esterases of cow's milk. J. Dairy Sci., 42, I903-I9I2.

Frankel, E. N., Tarrasslik N. P., 1956. The specificity of milk lipase. I. Determination of the lipolytic activity in milk toward milk fat and simpler esters. J. Dairy Sci., 39, 1506-1516.

Gordon W. G., Groves M. L., BASCh J. J., 1963. Bovine milk " red protein" amino acid composition and comparison with blood transferrine. Biochemistry, 2, 817-820.

Gordon W. G., Semuett W. F., 1953. Isolation of crystalline $\alpha$-lactalbumin from milk. J.am. chem. Soc., 75, 328-33o.

Gordon W. G, Seymetr W. F., Ziegler J., i954. Crystalline $x$-lactalbumin : an improved method for its isolation. Sulfur distribution. J. amer. Chem. Soc., 76, 287.

Gordon W. G., Ziecler J., 1955. Amino acid composition of crystalline- $\alpha$ lactalbumin. Arch. Biochem. Biophys., 57, 80-86.

Gordon W. G., Zregler J., Basch J. J., 1962. Isolation of an iron binding protein from cow's milk. Biochim. Biophys. Acta, 60, 410-4II.

Greenbank G. R., 1954. The xanthine oxydase (Schardinger's enzyme) content of dairy products and its inhibition by heat. J. Dairy Sci., 37, 644.

Groves M. L., 1960. The isolation of a red protein from milk. J. am. Chem. Soc., 82, 3345-3350.

Groves M. I., Bascil J. J., Gordon W. G., I963. Isolation characterization and amino acid composition of a new crystalline protein, lactollin, from milk. Biochemistry, 2, 814-81 7.

Gugler E. von, BEIN M., Muralt G. von, I959. Über immunoelektrophoretische Untersuchungen an Kuhmilchproteinen. Schweiz. Mediz. Wochen, 89, I 7 2-I I 76.

Guittonneau G., Chevalier R., Jarrousse H., i 944 . Sur la présence dans le lait de vache de deux pyrophosphatases accumulables dans le beurre et le babeurre. $C$. R. Acad. Sci., 218, 1006.

GUY E. J., JENness R., I958. Separation, concentration and properties of alpha-amylase from cow's milk. J. Dairy Sci., 41, $13^{-27}$.

Hanson L. A., 1959. Immunological Analysis of Bovine Blood, Serum and Milk. Comparative analysis of human milk and human blood plasma by means of diffusion in gel methods. Experientia, 15, $471-475$.

Harper W. J., Gould I. A., Badami M., 1956. Separation of the major components of the milk lipase system by supercentrifugation. J. Dairy Sci., 39, 9 I0.

Harper W. J., Schwartz D. P., EL Hagarawy I. S., 1956. A rapid silica-gel method for measuring free fatty acids in milk. J. Dairy Sci., 39, 46.

Herald C. T., Brunner J. R., I957. The fat globule membrane of normal cow's milk. The isolation and characteristics of two membranes protein fraction. J. Dairy $S c i ., 40,948-95^{6}$.

Hipp N. J., Groves M. L., Custer J. H., McMeekin T. L., I952. Separation of $\alpha$ - $\beta$ - and $\gamma$-caseins. J. Dairy Sci., 35, 272-28I.

Hippel P. H. von, Waugh D. F., I955. Casein-Monomers and Polymers. J. amer. Chem. Soc., 77, 431 I4319.

JACQuet J., SAIngt O., 1952. Les phosphomonoesterases du lait de vache. C. R. Soc. biol., Paris, 146, I 5 I 5-I 5 I 8 .

Annales de Biologie animale. - r964. 
JENNesS R., 1959. Characterization of milk serum protein component 5. J. Dairy Sci., 42; 895.

Jenness R., Larson B. L., McMeekin T. L., Swanson A. M., Whitnah C. H., Whitney R. Mcl., 1956. Nomenclature of the proteins of bovine milk. J. Dairy $S$ ci., 39, 536-541.

Kay H. D., Graham W. R., 1935. The phosphatase test for pasteurised milk. J. Dairy Res., 6, I9I-203.

Kenyon A. J., ANDERson R. K., Jenness, R., 1959. Isolation of immune globulins from milk and colostrum with Rivanol. J. Dairy Sci., 42, 1233 -1234.

Klostergaard H., Pasternak R. A., i957. Electrophoresis and ultracentrifuge studies of milk proteins. II. $\alpha$-lactalbumin. J. amer. Chem. Soc., $79,5674-5676$.

Larson B. L., Gillespie D. C., I957. Origin of the major specific proteins in milk. J. Biol. Chem., 227, $565-573$.

LaRson B. L., Hageman E. C., 1963 . Determination of $\alpha$-lactalbumin in complex systems. J. Dairy Sci., 46, 14-I8.

LARSON B. L., JENness R., 1955. Identification of $\alpha$-lactalbumin in the electrophoretic pattern of milk serum proteins. J. Dairy Sci, 38, 31 3-3I5.

LARSON B. L., Rolleri G. D., 1955. Heat denaturation of the specific serum proteins in milk. J. Dairy Sci., 38, $351-360$.

LARSON B. L., Twarog J. M., 196r. Determination of $\beta$-lactoglobulin in complex systems by a simple immunological procedure. J. Dairy Sci., 44, $1843^{-1} 85^{6}$.

Laskowski M. Jr, Laskowski M., i95x. Crystalline trypsin inhibitor from colostrum. J. Biol. Chem., $190,563$.

LiNDERSTRom-LANG, JACOBSEN C. F., 194r. The contraction accompanying enzymatic breakdown of proteins. C. R. trav. Lab. Carlsberg, 24, série Chim., I.

Lissitzky S., Rolland M., LaSRy S., 1960. Oxydation de la ribonucléase et de l' $\alpha$-lactalbumine par la polyphénoloxydase de champignon. Bioch. Biophys. Acta, 39, 379-380.

MARQUARDT R. R., Forster T. L., 1962. Arylesterase activity of bovine milk as related to incidence of mastitis. J. Dairy Sci., 45, 653 .

McMeekin T. L., i954. In Neurath H., and Bailey K., "The P'roteins". Vol. II, part. A, 389-434, Academic Press, New York.

Mealhy A. C., I954. The assay of catalases and peroxydases. In Glick, Met. Biochem. Analysis, 1, 386-408. Intersc. Pub. New York.

Mocquot G., Alais C., Chevalier R., I954. Étude sur les défauts de coagulation du lait par la présure. Ann. Technol. agric., 1, I-44.

Montgomery M. W., Forster T. L., I 96r. Partial purification of the $\beta$-esterase of bovine milk. J. Dairy Sci., 44, 721 .

Montreuil J., Anthony N., Descamps J., Durguesne N., 1963. Étude des glycoprotéides du lait de femme et de vache. Ann. Biol. anim. Bioch. Biophys., 3, $\mathrm{n}^{0}$ hors série, $\mathrm{r} 29-\mathrm{r} 33$.

MorRison M., HamiltoN H. B., STOTZ E., 1957. The isolation and purification of lactoperoxydase by ion exhange chromatography. J. Biol. Chem., 228, $767-776$.

Morton R. K., 1953. Alkaline phosphatase of milk. II. Purification of the enzyme. Biochem. J., 55, $795-800$.

Morton R. K., 1954. The lipoprotein particles in cow's milk. Biochem. J., 57, 231-237.

MüldDer G. J., 1838. Zusammensetzung von Fibrin, Albumin, Leinzucker, Leucin, u. s. w. Ann. Pharm., 28, 73 .

Murthy G. K., Whitney R. Mcl., I958. A comparison of some of the chemical and physical properties of $\gamma$-casein and immune globulins of milk. J. Dairy Sci., 41, I-I 2 .

OGston A. G., TombS M. P., I957. The heterogeneity of bovine $\beta$-lactoglobulin. Biochem. J., 66, 399-403.

Oudin J., I948. L'analyse immunochimique qualitative. Méthode par diffusion des antigènes au sein de l'immunsérum précipitant gélosé. Ann. Inst. Pasteur, 75, 30-5I.

PALmer A. H., 1934. The preparation of a crystalline globulin from the albumin fraction of cow's milk. J. Biol. Chem., 104, 359-372.

Pedersen K. O., 1936 a. Ultracentrifugal and electrophoretic studies on the milk proteins. I. Introduction and preliminary results with fractions from skim milk. Biochem. J., 30, 948-960.

Perdersen K. O., I936 $b$. Ultracentrifugal and electrophoretic studies on the milk proteins. II. The lactoglobulin of Palmer. Biochem. J., 30, 961-970.

Piez K. A., Davie E. W., Folk J. E., Gladner J. A., I96r. B-lactoglobulins A and B. I. Chromatographic separation and amino acid composition. J. Biol. Chem., 236, 2912-2916.

Polis B. D., Shmukler H. W., I950. Aldolase in bovine milk. J. Dairy Sci., 33, 619-622.

Polis B. D., Shmukler H. W., I953. Crystalline lactoperoxydase. I. Isolation by displacement chromatography. II. Physicochemical and enzymatic properties. J. Biol. Chem., 201, 475-500.

Polis B. D., Shmukler H. W., Custer S. H., I950. Isolation of a crystalline albumin from milk. $J$. Biol. Chem., 187, 349-354.

Portmann A., Auclair J. E., i 959 a. Relation entre les lactosérums et les agglutinines du lait de vache Ann. Inst. Pasteur, 97, 590-596. 
Portmann A., Auclair J. E., I959 b. Relation entre la lacténine $\mathrm{L}_{2}$ et la lactoperoxydase. Le Lait, 39, I $47^{-1} 5^{8 .}$

Rapport de la Commission sur les Enzymes de l'Union Internationale de Biochimie (г96r). Pergamon Press New York, N. Y., p. I04.

REID K., I931. Untersuchungen über den katalasegehalt der kuhmilch. Milch. Forsch., 11, 590-599.

Rolleri G. D., Larson B. L., Touchberry R. W., 1956. Protein production in the bovine breed and individual variations in the specific protein constituents of milk. J. Dairy Sci., 39, I683-I689.

Rowland S. J., 1937. The soluble protein fraction of milk. J. Dairy Res, 8, 6-I4.

Rowland S. J., r938 a. The precipitation of the proteins in milk. I. Casein. II. Total proteins. III. Globulins. IV. Albumin and proteose peptone. J. Dairy Res., 9, 30-41.

Rowland S. J., I938 b. The determination of the nitrogen distribution in milk. J. Dairy Res., 9, 42-46.

SMiтh E. L., 1946. Isolation and properties of immune lactoglobulins from bovine whey. J. Biol. Chem., $165,665-676$.

Sorensen M., Sorensen S. P. L., 1939. The Proteins whey. C. R. Tran. Lab. Carlsberg, Ser. Chim." 23, 55 .

Tarassuk N. F., Frankel E. N., I957. The specificity of milk lipase. IV. Partition of the lipase system in milk. J. Dairy Sci., 40, 4I8-430.

Thompson M. P., Brunner J. R., 1959. The carbohydrates of some glycoproteins of bovine milk J. Dairy Sci., 42, 369-370.

Tilley J. M. A., 1960. The chemical and physical properties of bovine $\beta$-lactoglobulin. Dairy Sci. Abstr., 22, I I I-I 25.

TimashefF S. K., Townend R., ig6r a. Molecular interactions in $\beta$-lactoglobulin. V. The association of the genetic species of $\beta$-lactoglobulin below the isoelectric point. J. amer. chem. Soc., 83, 464-469.

Timasheff S. N., Townend R., Ig6r $b$. Molecular interactions in $\beta$-lactoglobulin. VI. The dissociation of the genetic species of $\beta$-lactoglobulin at acid $\mathrm{pH}$ 's. J. amer. chem. Soc., 83, 470-473.

Townend R., Kiddy C. A., TimashefF S. N., г96r. Molecular interactions in $\beta$-lactoglobulin. VII. The "Hybridization " of $\beta$-lactoglobulins A et B. J. amer. Chem. Soc., 83, I419-1423.

Townend, R. Winterbottom R. J., TimashefF S. N., ig6o. Molecular Interactions in $\beta$-Lactoglobulin. II. Ultracentrifugal and Electrophoretic Studies of the Association of $\beta$-Lactoglobulin below its, isoelectric point. J. amer. chem. Soc., 82, 316 $\mathrm{I}-3 \mathrm{I} 68$.

Wake R. C., BALDWIN R. L., I96r. Analysis of casein fractions by zone electrophoresis in concentrated urea. Bioch. Biophys. Acta, 47, 225-239.

Warner R. C., Polis Ii., 1945. On the presence of a proteolytic enzyme in casein. J.amer. Chem. Soc. 67, 529 .

Weinstern B. R, Duncan C. W., Trout G. M., i95I. The solar activated flavor of homogeneized milk. IV. Isolation and characterization of a whey constituent capable of producing the solar activated flavor. J. Dairy Sci., 34, 570-576.

Wetlaufer D. B., 196r. Osmometry and general characterization of $\alpha$-lactalbumin. C. R. Trav. Lab. Carlsberg, 32, I $25^{-1} 3^{8}$.

Whitney R. Mcl., 1958. The minor proteins of bovine milk. J. Dairy Sci., 41, 1303-1 323.

Wright R. C., Tramer J., I958. Factors influencing the activity of cheese starters. The role of milk peroxydase. J. Dairy Res., 25, 104-I 8. 